\title{
FESTSCHRIFT
}

\section{A virtue ethics approach to moral dilemmas in medicine}

\section{P Gardiner}

J Med Ethics 2003;29:297-302

Most moral dilemmas in medicine are analysed using the four principles with some consideration of consequentialism but these frameworks have limitations. It is not always clear how to judge which consequences are best. When principles conflict it is not always easy to decide which should dominate. They also do not take account of the importance of the emotional element of human experience. Virtue ethics is a framework that focuses on the character of the moral agent rather than the rightness of an action. In considering the relationships, emotional sensitivities, and motivations that are unique to human society it provides a fuller ethical analysis and encourages more flexible and creative solutions than principlism or consequentialism alone. Two different moral dilemmas are analysed using virtue ethics in order to illustrate how it can enhance our approach to ethics in medicine.

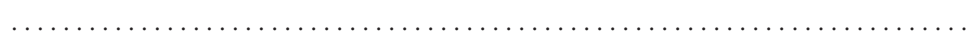

Correspondence to: P Gardiner, 5 London Road, Daventry, Northants NN 11 4DA, UK. patti@scottydoc.co.uk

Accepted for publication 20 June 2003 am not a philosopher. Neither am I an experienced ethicist. I am, rather, a general practitioner (GP), who deals with moral issues and dilemmas every day of my working life. These range from the daily awareness of distributive justice as I sign every prescription, to discussing and balancing the complex issues involved in choices made by patients with terminal disease. I find many of these situations challenging and some quite perplexing.

This is why I decided to study medical ethics at Imperial College London (ICL), where I was privileged not only to meet Professor Raanan Gillon but to be taught by him as well.

When I qualified as a GP in 1984, I had experienced no formal ethical teaching or training at all. By 1994 when I prepared to sit my Royal College of General Practitioners (RCGP) membership exam I was delighted to find that ethical teaching was firmly on the GP educational agenda. In general practice training, young doctors are raised on the four principles! This approach was initially developed in the United States by Beauchamp and Childress' ${ }^{1}$; but has been widely and enthusiastically advocated in the UK by Professor Gillon. ${ }^{2-4}$ Although there is some mention of the consequentialist approach, it is the four principles that win the day as a universally acceptable and practical way of considering moral issues. For non-philosophers it is an attractive prospect, when faced with an ethical difficulty, to have some simple, intelligible, and applicable guiding principles against which to measure any moral problem.
I am now an examiner for the RCGP membership exam and expect all candidates to not only be conversant with the four principles but also to be able to apply them appropriately. It is a tremendous credit to Professor Gillon that he has been such an effective mover and shaper of ethical understanding and judgment in British general practice.

During my studies at ICL I was introduced to a number of ethical frameworks and approaches, some of which were completely new to me. My understanding of moral reasoning grew considerably, but one approach captivated me and, I shall argue, adds a unique and essential dimension to ethical considerations.

\section{VIRTUE ETHICS}

Virtue ethics resonates with my experience of life in which the nature of our character is of fundamental importance. Ethical principles that tell us what action to take do not take into account the nature of the moral agent. Although we must make moral decisions with much care and consideration, I do not consider it wise to strip this process of affect or attitude and focus on reason alone. Humans are sophisticated creatures with an ability to reason that is tempered by our emotional reactions. These reactions are an integral part of how we perceive and assess the world around us but they also influence our judgments. Virtue ethics recognises this important component of our moral experience. It explores how moral agents can learn by habitual practise how to develop good characteristics that will enable us to behave well. I found it a refreshing and exciting discovery that the character of the moral agent could be of pivotal importance.

I shall briefly explain the fundamental concepts of virtue ethics in order to then demonstrate how such an approach can be used when considering two different medical ethical problems.

Virtue ethics began with the ancient Greek philosophers Socrates, Plato, and Aristotle. They searched for the elements that made a person good but in so doing they did not look at how a person acted but at what sort of character he had. They suggested that a good person who behaves well must develop virtues, which, through habitual use, become part of that person's character.

\section{The virtues}

So what is a virtue? Perhaps the most useful definition is that offered by Rachels, who suggests that a virtue is "a trait of character, manifested in habitual action, that it is good for a person to have". ${ }^{5}$

Aristotle believed that a virtue lay in the middle of two contrary vices and described it as "the mean by reference to two vices: the one of excess 
and the other of deficiency". ${ }^{6}$ Courage-for example, lies between foolhardiness and cowardice. Compassion lies between callousness and indulgence.

There is no comprehensive list of virtues. The cardinal virtues expounded by ancient Greek philosophers are courage, prudence, temperance, and justice. The theological virtues, faith, hope, and charity are not widely explored in secular moral philosophy although Toon has reviewed them in a medical context and shows them to be very useful. ${ }^{7}$ Beauchamp and Childress have considered five virtues applicable to the medical practitioner: trustworthiness, integrity, discernment, compassion, and conscientiousness (see reference 1, pp 32-8). Other modern philosophers have listed up to 24 possible virtues although some could be argued to be social rather than moral virtues. ${ }^{8}$

Philosophers may, in time, distil the growing list down to those that are essential and of core importance in order that humans may thrive.

\section{The meaning of life!}

Aristotle believed that the purpose of human existence is to achieve a state of eudaemonia, which is a difficult word to translate. "Happiness" is too superficial and subjective. We may feel happy if we satisfy our desires but this is no guarantee of any enduring contentment. To be eudaemon is rather to have the sort of happiness that is deep, lasting, and worth having. It is a deeply rooted joy in the dynamic process of our lives. It is hard to find a single word to sum up this concept but the closest approximation is "flourishing".

A human person flourishes and leads a good life when she fulfils the purpose and function of human beings. Philippa Foot encapsulated this wonderfully:

\section{Men and women need to be industrious and tenacious of purpose not only so as to be able to house, clothe and feed themselves, but also to pursue human ends having to do with love and friendship. They need the ability to form family ties, friendships and special relations with neighbours. They also need codes of conduct. And how could they have all these things without virtues such as loyalty, fairness, kindness and in certain circumstances obedience " $^{\prime 9}$}

The virtue ethicist has a deep understanding of the social and interpersonal nature of our human existence and how this can affect and be influenced by our moral behaviour.

\section{The place of reason}

Aristotle suggests that reason is the function unique to humans that sets them apart from all other living creatures. We have a capacity to make choices based on reason, which the most intelligent of higher order creatures do not appear to possess. Animals do not recognise ends as such and do not have the capacity for choosing to do something that will lead to a less good end when faced with two options (see reference 9, pp 25-51). It is by reasoning that a person determines how to act and feel in ways appropriate to a given circumstance. It is not sufficient to possess virtues; one must have the capacity to know when and how to exhibit them. Thus the virtuous person uses rationality (practical wisdom) to decide how to be.

In order to flourish, to be eudaemon, a person will possess virtues and exercise them with practical wisdom in order to make good choices in acting well. The virtues will become integral to her character and so become part of her flourishing, not just a means to that end. She will flourish as she makes virtuous choices and becomes wise, courageous, compassionate, and self controlled..$^{10}$ So the virtues benefit the possessor as they become deeply entrenched in a person's character such that she deeply desires to behave well.

\section{The role of emotion}

For centuries moral philosophers have approached ethical dilemmas by stripping away emotional responses and trying to reason out a solution, but our feelings are fundamental to our human experience. Indeed those with little or no emotional response are considered abnormal, untrustworthy, wicked or frankly dangerous-for example, those with psychopathic personality disorders.

In order to do something we must first perceive that an action is necessary. We must observe what's going on and recognise the morally pertinent aspects of the situation but ethical perception is not only a cognitive process. Emotional reactions make us sensitive to particular circumstances, and thus illuminate our perceptions. It is possible to perceive a situation dispassionately but we would then have an incomplete appreciation of the circumstances. Our emotions influence how and what we see and are necessary to register and record facts with resonance and depth. Equally what we see shapes how and what we feel. Thus perception and affect are closely intertwined in informing our choices. Undoubtedly our emotions need cultivating so that we learn towards whom, when, and to what degree we should express them. We need to exercise critical judgment when assessing and displaying our emotional responses. Emotions are not to be accepted as instinctive unmanageable reactions but as sensitivities that inform our judgments.

\section{The role of motivation}

The virtuous person perceives a situation, judges what is right, and wants to act accordingly because it is in her disposition to act well.

It is not sufficient to follow rules irrespective of internal attitudes, feelings, and reason. The virtuous moral agent has a deep desire to behave well. This contrasts with Kant's view: he believed it was more virtuous to act well from duty even if one is not disposed to do so. ${ }^{11}$ This may allow good action, but it does not encourage us to live well, and develop virtuous characteristics.

Imagine being visited in hospital by a friend; if the friend comes because she is compassionate, judges that it is the right thing to do and wants to visit, is this not more pleasing for you than if she comes purely because it is her duty? ${ }^{12}$ Is she not a kinder and more compassionate person if she wants to make your day better by visiting you than if she comes because she ought to? Do these qualities not enrich our lives as social beings with special relationships?

Virtue ethics's account of motivation surely sits well with human society in which we develop special bonds and alliances that encourage us to behave well out of friendship, love, and loyalty. It is these elements that bind communities together and it is the weakening of such commitments that are seen when communities begin to fragment.

\section{THE CASES}

Let me now turn to two different moral dilemmas. In one, a patient requests a course of action at variance with the professional judgment of his doctor. In the second I consider the moral implications of permitting individuals to sell kidneys. I shall show that by using a virtue ethics approach we can thoroughly examine the ethical difficulty that these cases present and can deduce a morally good plan of action. ${ }^{13}$

\section{Case 1: The "standard" Jehovah's Witness case}

A competent adult patient loses a massive amount of blood from a blood vessel bleeding in an acute duodenal ulcer. The best chance of saving his life is an urgent blood transfusion along with operative intervention to arrest the bleeding. The patient refuses blood but asks for treatment instead with the best available non-blood products, and surgery, accepting the 
substantial risk that surgery without blood transfusion is much less likely to save his life than surgery with blood transfusion.

\section{Background}

Health care professionals are usually motivated to improve the wellbeing of their patients. In pursuing this end, they must balance their expert knowledge and understanding with the preferences of their patients, taking into consideration the means by which that person has made their choice and ensuring they themselves do not transgress any medical moral code.

Doctors are bound by professional codes of practice with a strong emphasis on doing good and saving lives. Despite the current ubiquitous nature of the four principles, it is curious that since the 4 th century, the various codes of practice and oaths sworn by doctors declare a commitment to virtuous behaviour. $^{14-18}$

\section{The main intention of medical oaths seems to be to declare the core values of the profession and to engender and strengthen the necessary resolve in doctors to exemplify professional integrity, including moral virtues such as compassion and honesty. ${ }^{19}$}

Doctors in the 21 st century are encouraged to work in partnership with their patients, informing, guiding, advising, and helping them to make appropriate choices about how to deal with their illness. These choices are typically adapted to suit individuals, taking into consideration such factors as their health beliefs, cultural background, and social situation. The patient is likely to be deeply influenced by their upbringing, their personal priorities, the community in which they live, or indeed their faith. These factors may well influence them to make a choice that is at variance with the professional judgment of their doctor. This can be challenging when a patient chooses to reject a doctor's guidance-for example, refusing treatment, which the doctor knows may adversely affect her patient's wellbeing. Doctors are trained how to tolerate such uncertainty and the risks involved but when such a decision might affect the survival of the patient, the moral burden for the doctor can be tremendous.

\section{The patient}

If the patient is deemed competent to make decisions about his health, he is therefore competent to make decisions about his spiritual faith.

It is wise and prudent to respect the faith that an individual has chosen to follow of his own free will and under no duress. In a multicultural society, disparate groups will live more contentedly together and will thrive if they not only tolerate each other's differences but also respect each other. If they are able to seek commonality in their value systems they will deepen the important bonds of friendship and comradeship that bind their communities together.

As we have recognised, patients' understanding and beliefs will influence the priority they give to options in managing their health. In this situation the patient has chosen to prioritise what he believes is his eternal existence over that of his current physical health. He is prepared to take the risk that he might die in order to ensure, according to his own belief system, that he will have eternal life.

\section{The doctor}

The virtuous doctor examines the facts of the case, identifies her emotional response, which will illuminate and deepen her assessment of the situation, and considers the motivation of the patient and herself.

She may feel disappointment that her professional judgment is rejected, frustration that she cannot do her job as she would wish to, anxiety that the patient may die unnecessarily, and sorrow for the patient's family who may experience the death of their beloved relative.

Some of the emotional reaction is caused by the effect the patient's decision has in frustrating her professional purpose while some is a response to the possible outcome for the patient and his family.

Is she motivated to transfuse him to improve her productivity figures or does she genuinely want to help this individual patient find a solution to this particular predicament?

Is the patient motivated freely and sincerely by faith or is there an element of coercion from his religious community or indeed his family?

Having considered all these elements she then reflects on the virtues that would be most helpful in these circumstances.

Compassion is " . . an active regard for another's welfare with an imaginative awareness and emotional response of deep sympathy, tenderness and discomfort at another's misfortune or suffering."

In being compassionate, the doctor would imagine what it must be like to be a person who is prepared to risk death because of the sincerity and devotion to their faith. She is likely to recognise the courage of her patient, which in turn may provoke feelings of respect and admiration.

Trustworthiness is one of the corner stones of doctorpatient relationships. Patients bring their deepest and most personal concerns and problems, allow the most intimate of examinations, and confide their private vulnerabilities. They rely on the moral character and competence of their doctor and must be able to trust that their doctor will behave well.

The patient in our example has disclosed his profound faith and how much that influences his decisions about his future, even in the face of this dramatic and life threatening event. He has trusted his doctor with an insight into a profoundly personal part of his being. It is incumbent on all health care professionals to hold this trust securely and respond to it by being trustworthy.

In this situation it is very unlikely that we will be able to persuade the patient to change his ideology at this stage. If the doctor overrides the patient's request and imposes her medical solution upon him, the patient will have difficulty in trusting his doctor again and indeed may not trust the medical profession in the future.

Discernment brings sensitive insight, understanding, and wise judgment to the situation. A discerning doctor would identify the complex emotional elements of the case, would be able to weigh up her motivation to look after her patient's health as effectively as possible with the motivation of the patient whose life is founded on and underpinned by his faith even if devotion to his ideology costs him his life. She is likely to conclude that the discerning doctor would, with regret, respect the patient's wishes and not enforce a blood transfusion.

Regret: it is of importance to recognise the place of regret. Tragic dilemmas are typically very hard because there is a conflict in the principles being applied when trying to find a solution-for example, abortion in the case of rape. In much of the ethical literature there is a drive to find the correct solution, to try to decide which principles should take precedence or which consequences are preferable. After considerable debate, a course of action is chosen and is deemed to be the right thing to do. The moral agent need worry no more; they have done the right thing.

It is likely, however, that whatever actually happens, there will be regret for those involved; regret for what might have been, for the situation arising in the first place or for the undesirable effects of the action on those involved. Virtue ethics, because of its focus on the agent rather than the act, encourages moral agents to take account of and express the pain and regret they may experience when negotiating solutions to tragic dilemmas. It displays a sensitivity and concern that may go some way towards helping those who are 
experiencing it to come to terms with the situation. While consequentialists and deontologists do undoubtedly experience regret it would be an enhancing addition to their approach to express it more explicitly rather than focus entirely on the rightness of their action. ${ }^{20}$

\section{Conclusion}

In summary the virtue ethicist, after fully exploring the facts and considering the ethical sensitivities, would conclude that a compassionate, trustworthy, and discerning doctor would characteristically respect this patient's' wishes in this situation. This does not, however, amount to a rule.

One of the attractions of virtue ethics is the flexibility to assess each situation individually, searching for action guidance in considering what a characteristically virtuous person would do. This would be illuminated and informed by the relevant facts and individual ethical sensitivities of that circumstance. This allows and encourages creative solutions to very hard problems, which might be more difficult to find when applying rules and principles. If-for example, the adult patient in our case was a 19 year old born into a Jehovah's Witness community who felt an obligation to make decisions based on his parents' faith system while not truly believing it, the moral assessment might be quite different. The doctor may deduce that a different course of action would be virtuous.

\section{Case 2: Selling kidneys for transplantation: should} people be allowed to sell kidneys for transplantation ${ }^{13}$ Kidney donation is a vital process whereby people with renal failure who suffer chronic invalidity can, after transplantation, be restored to reasonable health, a substantially better quality of life, and improved life expectancy. Most donated organs are cadaverous, given by relatives of individuals who have died but still have viable internal organs. The supply of such kidneys is not enough to provide for those patients who wait and, not infrequently, die of renal failure while on the transplant waiting list. Some kidneys are donated from living individuals who are usually relatives, close friends or, more rarely, willing volunteers. There is, nevertheless, a serious shortage of organs for transplantation. Permitting willing volunteers to sell a kidney could address this shortage but this suggestion raises serious ethical issues.

\section{The need for donor organs}

This is an important factor to consider as, in the absence of demand, kidney sales would be unnecessary. There are likely to be many citizens who are unaware that there is such a shortage of donor kidneys and have not considered the implications for those in renal failure and their relatives. Nor is it likely that all members of the general public have thought in any depth about the implications of donating their own organs should they die prematurely. A high profile campaign to educate ordinary people about the need for cadaver donation, with assurances about the rigorous requirements when defining time of death, is likely to considerably raise awareness. This could make a big impact on organ supplies. Enticing people to sell one of their own kidneys is an ineffective way of trying to increase that supply and has major implications for the donor.

\section{The rights of the individual}

It has been argued that as long as there are no unpleasant consequences for other people and as long as it does no harm, an individual has the autonomous right to do as he chooses with his own body. Forcing an action on an unwilling participant is not acceptable-for example, indecent exposure, assault, or rape but choosing to indulge in bungie jumping certainly is! Let us put aside the argument of rights, principles, or consequences, however, and approach this suggestion from a virtue ethics perspective.
What are the facts of the situation?

What is likely to be the situation of a person who would want to sell their kidney? To whom might they wish to sell? How much will they be paid? What safeguards are in place to protect the health of the donor and the recipient? What are the circumstances of donors and what dependants have they? Are donors psychologically and emotionally stable? Have they been subject to any duress? We require these facts to begin our analysis.

What emotions does such a proposal arouse?

Affect and cognition both contribute to our perception and must be considered together to achieve a comprehensive assessment. There is an instinctive distaste for the proposal that an individual should sell an irreplaceable part of his body thus compromising his future health. Why should this be? For most of us, life is precious and we desire a long, happy, and healthy existence. In order to do this, we must look after and maintain our bodies. There are very many people, however, who choose not to do so by selecting unhealthy lifestyles. They judge that the short term gain is worth the long term risk of poor health or premature death. Similarly, the potential donor may consider that money now is worth the risk of surgery, complications, or long term ill health. Indeed it takes considerable courage to take this risk.

Perhaps any distaste is influenced by wider factors. An industry trading in organs is likely to attract volunteers who have so much to gain from the payment that they are willing to take a substantial risk with their lives. In short they will probably be very poor or deprived. Surely a business such as this plays on the vulnerability of the poor and desperate. This situation generates feelings of sadness and pity for the deprived but also anger towards those who might make money from such a business. Those who are affluent and powerful could potentially profit financially from the despair of the underprivileged.

What are the likely motivations of the people involved? The risks to the donor of the operation and consequent life with only one kidney are substantial and would not be considered lightly.

The potential donor may be motivated by compassion for his dependants and decide that his health is worth risking for the benefit now to his family.

While he may well have concern for the recipient, it is unlikely that this is the driving force behind his decision because if this was a commercial enterprise there is no assurance that donors and recipients would ever know of each other as individuals.

It is not a realistic proposal that a person would feel so moved to improve the plight of those in renal failure that he would offer his kidney for sale. Donating one kidney may help one person only and does nothing for the plight of the thousands who are in renal failure. It is most likely that any potential donor is motivated by the financial reward.

Those who are willing to buy kidneys from willing donors could be so touched by the plight of those in renal failure that they are prepared to set up a commercial business to increase the supply of available organs. It could be set up in a carefully regulated fashion to ensure high quality medical care and follow up for donors and recipients alike. We must not assume the only motivation is money although it is unlikely that anyone would set up such a business to run at a loss. Should there be financial gain this makes it a more attractive and viable proposition.

It could be argued that those who set up such a business do so because they want to help those who are disadvantaged in society by offering them a way of making money. I do not think we need dwell long on this suggestion, as this is in reality a very ineffective way of tackling deprivation. Should this 
be their motivation it would be more likely that they would try to provide for such deprived people without expecting them to take such huge health risks.

I suggest that anyone setting up such a business has not thought through carefully the impact on those who are poor and marginalised in society. Is it likely that people who are financially secure would take such risks with their lives? I propose that the only supply of donors is likely to come from those who are poor, marginalised, or oppressed. The poorer and more desperate the person, the more attractive would be the offer to buy his kidney.

\section{Which virtues might guide our behaviour in such a} difficult dilemma?

Where is the justice in a society where some people are so poor or deprived they are prepared to sell their bodies for whatever function, be it kidney donation or prostitution? We have recognised that humans are social animals who thrive in communities where they establish special bonds of love and friendship. Those who experience deprivation or starvation devote their time and energy to their survival and have little reserves left to contribute to their community. So, if a society is to flourish, all individuals must achieve some minimally decent standards of living. This will require the community to be fair in its approach to the vulnerable, ensuring they are protected from exploitation and have some basic security. The creative and just way forward in this particular predicament might be to protect the vulnerable from exploitation while developing innovative ways of improving the supply of kidneys donated after death.

The compassionate person would care deeply about the plight of the deprived and marginalised. Although there may be occasions when such people have chosen to opt out of society's usual structure-for example, the homeless, travellers, or drug addicts, there is always some reason why they have done so, which stems from deprivation, whether that be economic, emotional, or social. Compassion would have us care so deeply that we would be moved to improve their situation.

The compassionate person would also care deeply about those with renal failure who need medical care and wait for suitable transplant opportunities. This must be balanced with the chronic suffering of the deprived but the two needs are not mutually exclusive. The virtuous moral agent would compassionately appreciate the desperation of both groups.

She would practise discernment in sensitively understanding those needs and using wise judgment to balance her compassion for those in renal failure and the deprived who may be enticed into selling organs. Having considered the facts, the emotional response, and the motivations of all concerned, she would look for creative solutions that might address the needs of both groups.

Rather than permitting sale of kidneys, society would flourish better if it ensured that the poor were adequately provided for, and that the supply of organs was actively pursued through education and promotion of cadaverous donation.

\section{Conclusion}

In summary the virtue ethicist would recognise the needs of both groups, would balance compassion for them both with the need to behave fairly towards all individuals, and would discern that there are creative ways of resolving the need for kidney donations and the needs of the disadvantaged. They would recognise the compelling arguments for protecting the vulnerable and would most certainly recommend that we do not behave well as a society if we permit the sale of kidneys for profit.

In these examples I have chosen a number of virtues that seem useful for my analysis. There may be others of relevance such as integrity, conscientiousness, or hope, which could be relevant in a more lengthy and detailed examination. There is no limit to which or how many virtues should or can be scrutinised but the prudent virtue ethicist would try to select those of greatest pertinence to a particular predicament.

\section{THE PLACE OF VIRTUE ETHICS}

When I began studying medical ethics I hoped I would learn the right answers to difficult moral dilemmas. I discovered to my disappointment but perhaps with some relief, that there are none! Instead, there are many different ways of approaching difficult moral dilemmas, which help to tease out justification for a particular course of action.

Consequentialists do what will produce the best consequences but debate revolves around how to define what is best. $^{21}$

Deontologists adhere to correct moral principles but how are we to decide which are the right principles? Professor Gillon has extensively demonstrated that the four principles are acceptable to people from widely disparate cultures and religions. ${ }^{4}$ But when they conflict how do we prioritise and decide which takes precedence?

Virtue ethics has a number of advantages over the four principles:

- It recognises that emotions are an integral and important part of our moral perception.

- It considers the motivation of the agent to be of crucial importance. Decisions are anchored in the characteristic virtuous disposition of the moral agent who typically wants to behave well.

- As there are no rigid rules to be obeyed, it allows any choices to be adapted to the particulars of a situation and the people involved. Two people might both behave well when resolving the same situation in different ways.

- This flexibility encourages the pursuit of creative solutions to tragic dilemmas.

- Virtue ethicists recognise that tragic dilemmas can rarely be resolved to the complete satisfaction of all parties and that any conclusion is likely to leave some remainder of pain and regret.

I do not suggest that virtue ethics is an ethical framework that is superior to or replaces those of consquentialism and deontology. I do propose that it deeply enhances our approach to moral dilemmas. Is it possible that the virtues are the foundations of morally decent behaviour? If we develop secure foundations, by habitually practising virtuous characteristics such as honesty, discernment, courage, and integrity then a desire to fulfil our duties and obligations will follow naturally. The consequences of living a virtuous life are likely to be good as such behaviour contributes to the dynamic process of human flourishing.

Moral agents who develop virtuous characteristics by such habitual practice will find that their nature becomes the embodiment of the values that encourage human flourishing.

In the words of St Thomas Aquinas: "Virtue is that which makes its possessor good, and his work good likewise". ${ }^{22}$

\section{REFERENCES}

1 Beauchamp T, Childress J. Principles of biomedical ethics [5th ed]. Oxford: Oxford University Press, 2001: 57-272.

2 Gillon R. Philosophical medical ethics London: Wiley, 1985.

3 Gillon R. Medical ethics: four principles plus attention to scope. BM 1994;309: 184-8

4 Gillon R, Lloyd A, eds. Principles of health care ethics. London: Wiley, 1994.

5 Rachels J. The elements of moral philosophy. London: McGraw-Hill International, 1999: 178.

6 Aristotle. Nicomachean ethics [translated by Thompson JAK]. London: Penguin, 1976.

7 Toon P. Towards a philosophy of general practice. Occasional paper 78. London: Royal College of General Practitioners, 1999.

8 Comte-Sponville A. A short treatise on the great virtues. London: William Heinemann, 2002

9 Foot P. Natural goodness. Oxford: Oxford University Press, 2001

10 Sherman N. The fabric of character. Oxford: Oxford University Press, 1989:7. 
11 Kant I. Good will, duty and the categorical imperative [translated by Abbott TK]. In: Sommers C, Sommers F, eds. Vice and virtue. London: Harcourt College Publishers, 2001.

12 Stocker $M$. The schizophrenia of modern ethical theories. J Philos 1976;73:453-66.

13 Gillon R. Four scenarios. J Med Ethics 2003;29:267-8.

14 Hippocrates. The Hippocratic oath: text, translation, and interpretation [translated by Edelstein L]. Baltimore: Johns Hopkins Press, 1943.

15 Maimonides. Oath and prayer of Maimonides [translated by Friedenwald H]. Bull Johns Hopkins Hosp 1917;28:260-1.

16 Lasagna L. Hippocratic Oath-modern version. www.pbs.org/ and follow the links for the index (accessed 15 September 2002).
17 Robin E. The Hippocratic oath updated. BMU 1994:309:952.

18 World Medical Association. Declaration of Geneva. London: World Medical Association, 1995.

19 Hurwitz B, Richardson R. Swearing to care: the resurgence in medical oaths. BM 1997;315:1671-4.

20 Hurtshouse R. On virtue ethics. Oxford: Oxford University Press, 1999.

21 Mill JS. Utilitarianism. In: Sommers C, Sommers F, eds. Vice and virtue. London: Harcourt College Publishers, 2001

22 Aquinas St T. The Summa theologica of St Thomas Aquinas [translated by fathers of the English Dominican Province]. New York: Benziger Brothers, 1947.

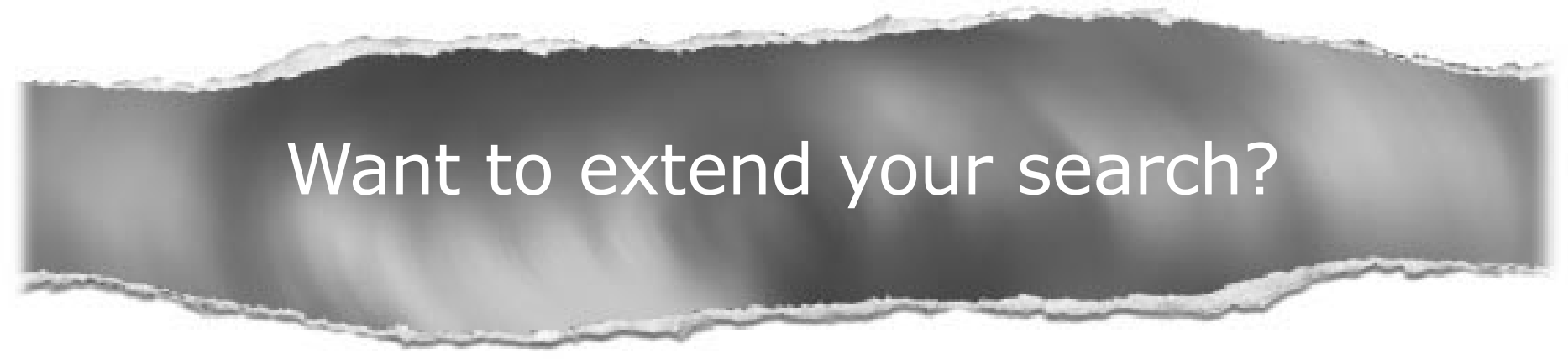

\section{Cross journal searching}

Can't find what you're looking for in Journal of Medical Ethics? Extend your search across 340+ journals. Search restriction options include specific subject areas (eg. clinical medicine, basic research), select specific journals or search all available titles.

www.jmedethics.com 